\title{
Minerais pesados das porções média e superior do Grupo Guaritas (Eocambriano, RS): considerações sobre a proveniência sedimentar
}

\author{
Jorge Emanuel dos Santos Nóbrega ${ }^{1}$, André Oliveira Sawakuchi ${ }^{2}$ \& Renato Paes de Almeida ${ }^{2}$
}

\begin{abstract}
Resumo O Grupo Guaritas abrange sedimentos de sistemas deposicionais de leques aluviais, fluviais e eólicos. Este estudo envolveu a análise de minerais pesados das formações Varzinha, Pedra Pintada, Pedra da Arara e Serra do Apertado, unidades das porções média e superior do Grupo Guaritas. Essas análises foram realizadas na fração areia muito fina de 29 amostras coletadas em afloramentos e abrangeram a quantificação da assembléia de minerais pesados transparentes não-micáceos, além da determinação dos índices ZTi (zircão/(turmalina+zircão)) e ZRi (zircão/(rutilo+zircão) e tipos morfológicos de zircão. As amostras estudadas correspondem a subarcóseos, sublitoarenitos e litoarenitos. Os minerais pesados identificados foram: zircão (82-13\%), apatita (64-0\%), turmalina (41-3\%), anatásio (22-0\%), granada (29-0\%), rutilo (10-0\%), sillimanita (5-0\%), monazita (4-0\%), epidoto (2-0\%), cianita (1-0\%) e fluorita (1-0\%). Foram reconhecidas quatro classes morfológicas de zircão: prisma curto superarredondado/arredondado (47-6\%), prisma curto subarredondado/ subédrico (92-42\%), prisma curto euédrico (13-0\%) e prisma longo euédrico (3-0\%). A abundância de zircão, apatita e turmalina associada a quantidades muito reduzidas de minerais tipicamente metamórficos, tais como rutilo, sillimanita e cianita, é compatível com área-fonte dominada por rochas ígneas graníticas. Grãos superarredondados de zircão indicariam ainda a presença de rochas sedimentares na área-fonte. Valores similares dos índices ZRi $(0,92-0,96)$ e ZTi $(0,71-0,82)$ nas unidades do Grupo Guaritas apontam, respectivamente, a manutenção da configuração das áreas-fonte e pequena variação do grau de retrabalhamento dos sedimentos. A Formação Serra do Apertado distingue-se das demais unidades pelos valores mais elevados de ZTi e pela maior proporção de grãos euédricos de zircão. Isso indica maior retrabalhamento dos seus sedimentos, com incremento dos sedimentos derivados de rochas ígneas em relação aos derivados de rochas metamórficas e sedimentares durante a fase final de preenchimento da Bacia do Camaquã.
\end{abstract}

Palavras-chave: proveniência, petrografia, minerais pesados, Grupo Guaritas, Bacia do Camaquã.

\begin{abstract}
Heavy minerals from the middle and upper portions of the Guaritas Group (Eocambrian, $R S)$ : some remarks about their sedimentary provenance. The Guaritas Group comprises sediments from alluvial fan, fluvial and eolian depositional systems. This study aimed with the heavy mineral analysis of sandstone samples from Varzinha, Pedra Pintada, Pedra da Arara and Serra do Apertado formations, units from the middle and upper portions of the Guaritas Group. For the heavy mineral analysis, it was used the very fine sand fraction of 29 samples collected in outcrops. This analysis included the identification and counting of the non-opaque and non-micaceous heavy minerals as well as the determination of the ZTi (zircon/ (tourmaline+zircon)) and ZRi (zircon/(rutile+zircon) indexes and morphological types of zircon grains. The studied samples correspond to subarkoses, sublitharenites and litharenites. The identified heavy minerals were: zircon (82-13\%), apatite (64-0\%), tourmaline (41-3\%), anatase (22-0\%), garnet (29-0\%), rutile (10-0\%), sillimanite (5-0\%), monazite (4-0\%), epidote (2-0\%), kyanite (1-0\%) and fluorite (1-0\%). There were recognized four morphological types of zircon grains: very well/well rounded short prism (47-6\%), subrounded/subeuhedral short prism (92-42\%), euhedral short prims (13-0\%) and euhedral long prims (3-0\%). The huge quantity of zircon, apatite and tourmaline grains (common accessory minerals in nearby granitic rocks) and the reduced proportion or absence of typically metamorphic heavy minerals like rutile, sillimanite, kyanite, staurolite, amphiboles and pyroxenes, are compatible with source area dominated by igneous acid rocks (granites). Very well rounded grains of zircon still indicate sediments from ancient sedimentary rocks. Similar values of the ZRi (0.92-0.96) and ZTi (0.71-0.82) indexes suggest, respectively, maintenance of the source area configuration and minor variation of the sedimentary reworking degree during the deposition of the middle and upper portions of the Guaritas Group. The Serra do Apertado Formation slightly differs from the other units by its relative higher ZTi and proportion of euhedral zircon grains. This is indicative of higher degree of sedimentary reworking and increasing contribution of sediments derived from igneous rocks during the final phase of sedimentary fill of the Camaquã basin.
\end{abstract}

Keywords: provenance, petrography, heavy minerals, Guaritas Group, Camaquã Basin.

1 - Programa de pós-graduação em Geoquímica e Geotectônica (IGc-USP), Instituto de Geociências, Universidade de São Paulo, São Paulo (SP), Brasil. E-mail: jorge.nobrega@usp.br.

2 - Instituto de Geociências, Universidade de São Paulo, São Paulo (SP), Brasil. E-mails: andreos@usp.br, rpalmeid@usp.br 
INTRODUÇÃO O Grupo Guaritas (Eocambriano da Bacia do Camaquã) é formado por rochas siliciclásticas, predominantemente arenosas e conglomeráticas, interpretadas como de origem aluvial e eólica (Robertson 1966, Lavina et al. 1985, Paim 1994, Almeida 2005). Esta unidade estratigráfica contempla mais de $1000 \mathrm{~m}$ de espessura de sedimentos e abrange as formações Guarda Velha, Pedra das Torrinhas, Varzinha, Pedra Pintada, Pedra da Arara e Serra do Apertado. Estas unidades representam a fase final de preenchimento sedimentar da Bacia do Camaquã, a qual desenvolveu-se em área que seria posteriormente recoberta por ampla bacia intracratônica, a Bacia do Paraná. Assim, o Grupo Guaritas relaciona-se a importantes eventos geológicos do sul do Brasil, pois registra o encerramento da sedimentação na bacia extensional do Camaquã durante o Cambriano, que precede o ínicio da sedimentação na Bacia do Paraná (Ordoviciano). Análises de minerais pesados de unidades sedimentares paleozóicas brasileiras, tais como as que compõem o Grupo Guaritas, são escassos. Este trabalho teve como objetivo a análise de minerais pesados e seções delgadas, orientada por levantamentos estratigráficos e análise de fácies, das unidades das porções média e superior do Grupo Guaritas (formações Varzinha, Pedra Pintada, Pedra da Arara e Serra do Apertado). As informações obtidas serviram de base para interpretação das rochas-fonte e das condições climáticas atuantes durante a deposição dos sedimentos estudados.

\section{GEOLOGIA DA ÁREA DE ESTUDO}

Contexto Tectono-Estratigráfico A Bacia do Camaquã está localizada na região centro-sul do Rio Grande do Sul e corresponde a uma bacia distensional do tipo rifte (Fragoso-Cesar 1991, Fragoso-Cesar et al. 1999). O Grupo Guaritas (Supergrupo Camaquã) ocorre alojado, em contato tectônico, entre os altos do embasamento da serra das Encantadas e de Caçapava do Sul, sendo que recobre parcialmente este último alto estrutural. Seus depósitos sedimentares são representados por uma faixa de direção NNE-SSW, com cerca de $50 \mathrm{~km}$ de largura e mais de $150 \mathrm{~km}$ de extensão, a qual é recoberta por depósitos permianos da Bacia do Paraná em suas extremidades (Fig. 1). O embasamento do Grupo Guaritas aflora a sul, sendo constituído por complexos metamórficos e plutônicos das unidades brasilianas da região, as quais incluem o flanco ocidental do Cinturão Dom Feliciano e seu limite com o Terreno Rio Vacacaí, além do extremo setentrional do Cráton do Rio de La Plata (Fragoso-Cesar 1980, 1991). As estruturas tectônicas desse embasamento foram reativadas diversas vezes, durante e após a instalação do rifte (Almeida 2005).

Além de rochas ígneas e metamórficas, o Grupo Guaritas sobrepõe-se a sucessões não-metamórficas com mais de $10 \mathrm{~km}$ de espessura das unidades mais antigas do Supergrupo Camaquã, as quais foram deformadas de modo rúptil e dispostas em camadas com direções em torno de NNE-SSW e mergulhos entre $20^{\circ}$ e $50^{\circ}$ ou localmente sub-verticais (Almeida 2005). Segundo este autor, estas sucessões foram depositadas na Bacia do Camaquã durante o período Ediacarano e compõem as seguintes unidades: Grupo Maricá (siliciclástico), Grupo Bom Jardim (vulcano-sedimentar), Formação Acampamento Velho (vulcânica) e Grupo Santa Bárbara (siliciclástico). A Bacia do Camaquã foi compartimentada em três sub-bacias durante a sedimentação do Grupo Santa Bárbara: Camaquã Ocidental, Camaquã Central e Camaquã Oriental, sendo que a estruturação da Sub-Bacia Camaquã Central coincide com a do rifte ao tempo da deposição do Grupo Guaritas (Almeida 2005).

O Grupo Guaritas O Grupo Guaritas (Fig. 2), correspondente ao topo do Supergrupo Camaquã, é formado por arenitos conglomeráticos, conglomerados, ritmitos psamo-pelíticos e arenitos finos a médios com séries métricas de estratificação cruzada ou plano-paralela, interpretados como registro de sistemas deposicionais continentais (Robertson 1966, Lavina et al. 1985, Paim 1994, Almeida 2005). Seus arenitos apresentam intensa cimentação carbonática e correspondem, principalmente, a arcóseos e, subordinadamente, a arenitos líticos (De Ros et al. 1994, Almeida 2005).

A Formação Guaritas de Robertson (1966) excluía os depósitos eólicos, considerados como parte da Formação Santa Bárbara por Ribeiro et al. (1966). O primeiro trabalho em que consta a interpretação de origem eólica para arenitos da Formação Guaritas resultou de mapeamento geológico na região do Passo do Tigre, no extremo sudoeste da Bacia do Camaquã por Becker \& Fernandes (1982).

Fragoso-Cesar et al. (1984) e Fragoso-Cesar et al. (1985) registraram a presença de depósitos eólicos na região das Minas do Camaquã, atribuídos a dunas barcanas. Lavina et al. (1985) distinguiram depósitos de dunas, caracterizadas pelos padrões de estratificação descritos por Hunter $(1977,1981)$, e interdunas, caracterizadas por camadas com estratificações horizontais e intercalações de pelitos gretados.

Faccini et al. (1987) identificaram a presença de abundantes fácies de marcas onduladas, interpretadas como de fluxo oscilatório em ambiente praial, intercaladas às sucessões eólicas.

Paim (1994) realizou estudos detalhados nas principais exposições de arenitos eólicos do Grupo Guaritas, dividindo a sucessão eólica em três associações de fácies: (i) arenitos com estratificações cruzadas, (ii) depósitos horizontais heterolíticos delgados e (iii) depósitos horizontais heterolíticos espessos.

Paim et al. (1995) e Paim (1996) discutiram a subdivisão aloestratigráfica de toda a Bacia do Camaquã, com breves considerações acerca da sucessão eólica. Paim (1996) ainda destacou a importância das fácies de interdunas úmidas para a interpretação paleoambiental da sucessão eólica, caracterizando-a como um sistema eólico úmido.

Paim \& Scherer (2003) detalharam as interpretações de sistemas deposicionais e de evolução estratigráfica da seção-tipo da Formação Pedra Pintada, caracterizando associações de fácies flúvio-lacustre, de dunas eólicas e de interdunas. Essa divisão, suas descrições e interpretações são compatíveis à proposta por 


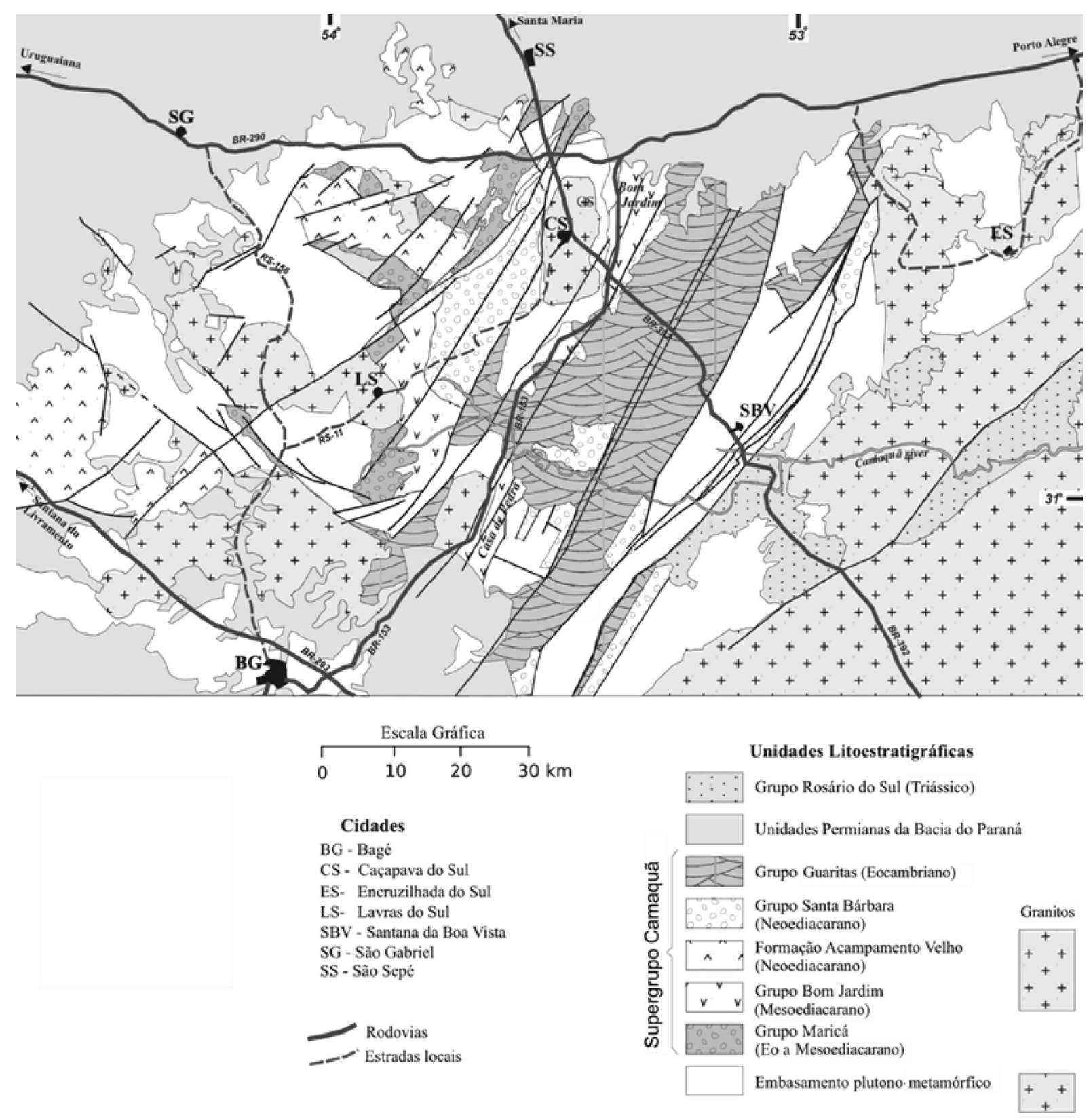

Figura 1 - Mapa geológico esquemático da Bacia do Camaquã e áreas vizinhas.

Almeida (2005), que detalhou as associações de fácies de dunas eólicas e interdunas e expandiu a identificação de super-superfícies e a caracterização da arquitetura deposicional na seção-tipo da unidade (Paim \& Scherer 2003). Quanto à posição estratigráfica das sucessões eólicas, Almeida (2005) discorda daquela que foi considerada por Paim (1994), Paim et al. $(1995,2000)$ e Paim $\&$ Scherer (2003). Enquanto Almeida (2005) revela que toda a sucessão eólica tem posicionamento estratigráfico inferior às sucessões aluviais (Formação Serra do Apertado), com a sucessão com paleoventos para SSW (Formação Pedra da Arara) abaixo da sucessão com paleoventos para NNE (Formação Pedra Pintada), Paim (1994), Paim et al. $(1995,2000)$ e Paim \& Scherer (2003) consideram a existência de duas aloformações eólicas distintas, separadas por depósitos aluviais equi- valentes às sucessões aluviais supracitadas.

Neste estudo, considera-se que o Grupo Guaritas teve sua deposição durante o Eocambriano, sendo adotada a subdivisão estratigráfica proposta por Almeida (2005). De acordo com este autor, o Grupo Guaritas compreende as seguintes formações:

Formação Guarda Velha: formada por arenitos, conglomerados e arenitos conglomeráticos de origem fluvial. Tratase da unidade mais basal do Grupo Guaritas.

Formação Pedra das Torrinhas: formada por arenitos conglomeráticos e conglomerados atribuídos à fácies de leques aluviais.

Formação Varzinha: apresenta ritmitos psamo-pelíticos interpretados como fácies fluviais e deltaicas.

Formação Pedra Pintada: possui arenitos finos com estratificação cruzada interpretados como fácies de dunas 


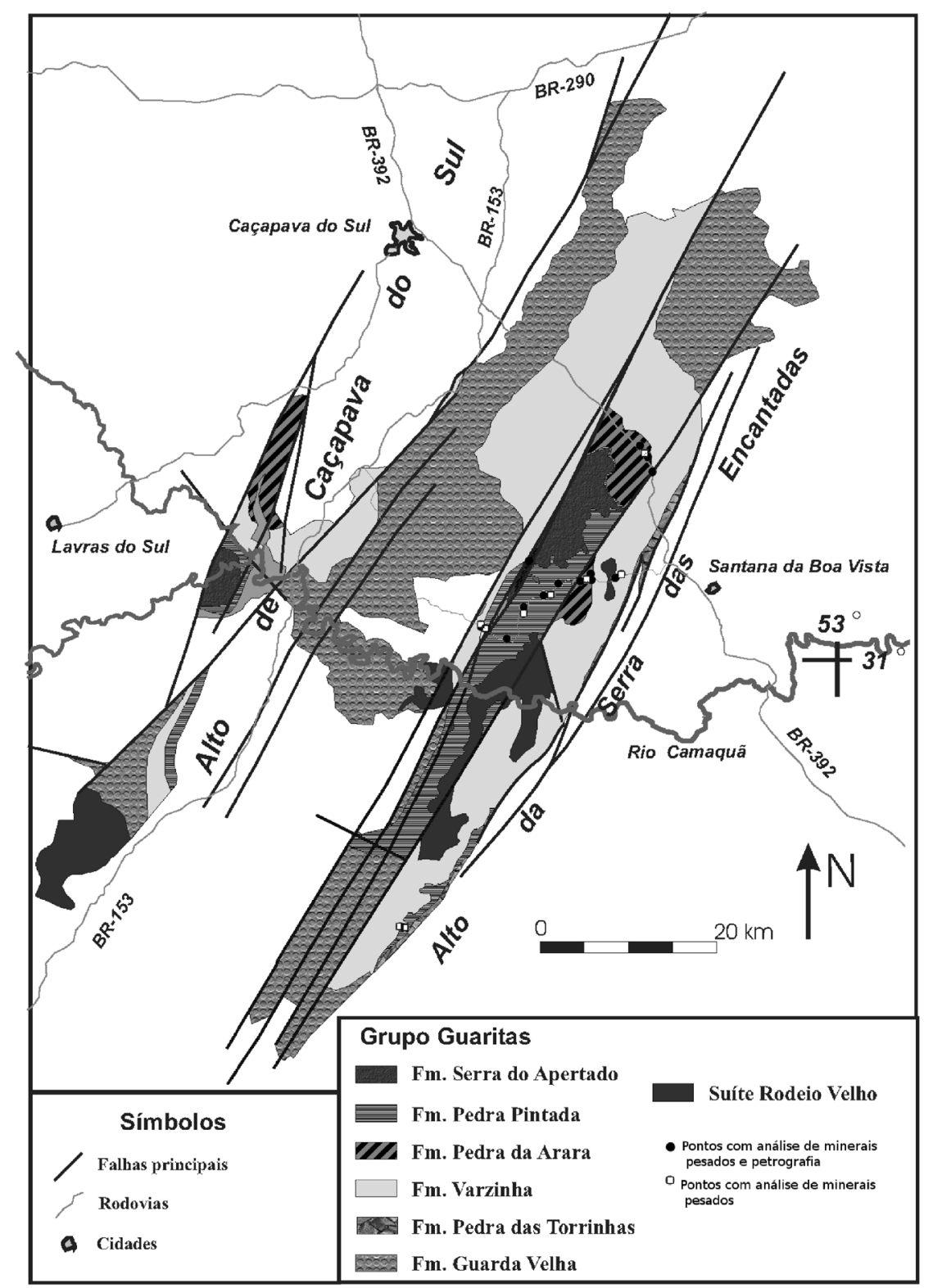

Figura 2 - Mapa geológico esquemático do Grupo Guaritas, com localização dos afloramentos descritos. Mapa baseado em Almeida (2005).

eólicas e raramente interdunas (arenitos finos com estratificação plano-paralela), além de arenitos finos a grossos e arenitos conglomeráticos fluviais. Suas fácies eólicas apresentam rumo de paleoventos para NE.

Formação Pedra da Arara: possui arenitos finos com estratificação cruzada (fácies de dunas eólicas) ou plano-paralela (fácies de interdunas). Ocorrem também arenitos conglomeráticos interpretados como fácies de canais de rios efêmeros. Suas fácies eólicas apresentam rumo de paleoventos para SW.

Formação Serra do Apertado: é formada por arenitos finos a grossos e conglomerados de origem fluvial.

\section{MATERIAIS E MÉTODOS}

Petrografia de seções delgadas Foram confeccionadas 20 lâminas delgadas de arenitos das unidades do
Grupo Guaritas, as quais foram utilizadas para descrição de aspectos texturais e composicionais do arcabouço, matriz e cimento, ao microscópio de luz polarizada transmitida. As amostras foram então classificadas segundo a proposta de Folk (1968). A caracterização petrográfica forneceu critérios auxiliares para definição das rochas-fonte dos sedimentos. Além disto, possibilitou o refinamento da descrição das fácies sedimentares.

\section{Análise de minerais pesados}

SEPARACÃO DE MINERAIS PESADOS E CONFECÇÃO DE LAMINAS DE GR AOOS Foram coletadas 29 amostras de arenitos e arenitos conglomeráticos das formações Varzinha, Pedra Pintada, Pedra da Arara e Serra do Apertado. As amostras foram fragmentadas e desagregadas manualmente em almofariz, com uso de 
pilão de borracha. Parte das amostras foi atacada com $\mathrm{HCl} 10 \%$, para redução do cimento carbonático. Posteriormente, as amostras foram elutriadas, para eliminação das frações silte e argila, e peneiradas para aquisição da fração granulométrica entre 0,063 e $0,125 \mathrm{~mm}$ (areia muito fina). Esta fração foi submetida a ensaio de flutuação-afundamento em líquido denso (bromofórmio, $\mathrm{CHBr}_{3}, \rho=2,85 \mathrm{~g} / \mathrm{cm}^{3}$ ), segundo os procedimentos descritos por Parfernoff et al. (1970), para separação entre as porções de minerais leves e pesados. Os minerais pesados foram então separados nas frações magnética e não-magnética com auxílio de imã de mão. Lâminas de grãos de minerais pesados não-magnéticos foram confeccionadas com bálsamo do Canadá.

QUANTIFICAÇÃO DA ASSEMBLÉIA DE MINERAIS PESADOS E DETERMINAÇÃO DE ÍNDICES MINERALÓGICOS (ZRi E ZTi) E TIPOS MORFOLÓGICOS $D E$ ZIRCÃO Os grãos de minerais pesados transparentes e não-micáceos foram identificados e quantificados ao microscópio petrográfico de luz transmitida. Os resultados de quantificação da assembléia total de minerais pesados foram utilizados para determinação de índices mineralógicos e de tipos morfológicos de zircão. A contagem de grãos de minerais pesados seguiu o procedimento de "ribbon counting", descrito por Galehouse (1971) e Mange \& Maurer (1992). Neste método, realiza-se a contagem de pelo menos 100 grãos de minerais pesados transparentes e não-micáceos ao longo de faixa selecionada de modo aleatório na lâmina delgada. De acordo com Van Andel (1950), não há diferenças significativas entre as proporções dos minerais mais abundantes quando contagens de 100 e 600 grãos de minerais são comparadas.

Hubert (1962) definiu o índice ZTR (somatório das proporções de zircão, turmalina e rutilo dentre os minerais pesados transparentes não-micáceos) como indicador de maturidade mineralógica de sedimentos arenosos, o qual poderia ser usado para correlação entre unidades sedimentares. No entanto, o índice ZTR combina minerais resistentes à dissolução química (zircão, turmalina e rutilo), porém com densidades relativamente distintas, o que implica susceptibilidade variável destes minerais ao transporte sedimentar. Assim, as variações do índice ZTR podem resultar do efeito combinado da alteração pós-deposicional e do transporte sedimentar. Isto dificulta sua interpretação em termos de proveniência sedimentar e sua utilização para correlação entre unidades estratigráficas. Morton \& Hallsworth (1994, 1999) forneceram parâmetros para comparação entre unidades sedimentares por meio da razão entre tipos específicos de minerais pesados. $\mathrm{O}$ significado genético destes índices depende do contraste entre as características químicas (resistência à dissolução) e físicas (resistência à abrasão, forma e densidade) dos minerais que compõem o respectivo índice. O índice ZRi, por exemplo, (grãos de zircão/(grãos de rutilo+zircão)) seria indicativo de mudanças de área-fonte primária, já que reúne minerais com características químicas e físicas semelhantes, portanto, pouco susceptível à modi- ficações pelo transporte sedimentar e alteração pós-deposicional. Baseado neste trabalho, definiu-se o índice formado pela razão entre o número de grãos de zircão e o número de grãos de turmalina+zircão (ZTi). O contraste de densidade entre zircão $\left(4,6\right.$ a $\left.4,7 \mathrm{~g} / \mathrm{cm}^{3}\right)$ e turmalina $\left(2,9\right.$ a $\left.3,1 \mathrm{~g} / \mathrm{cm}^{3}\right)$ torna os grãos de turmalina mais susceptíveis ao transporte em relação aos grãos de zircão, o que tornaria a unidade fonte relativamente rica em zircão. Seguindo este raciocínio, este índice seria indicador do grau de retrabalhamento sedimentar, sendo que sedimentos mais retrabalhados apresentariam valores maiores de ZTi, devido à concentração residual de zircão na fonte. Assim, foram computados os índices ZRi e ZTi por meio da contagem de 100 grãos dos minerais que compõem o respectivo índice.

Também foi realizada a quantificação de tipos morfológicos de grãos de zircão, os quais foram definidos pelo grau de arredondamento e proporção entre os eixos maior e menor. A proporção entre tipos morfológicos de zircão pode ser interpretada puramente em termos de proveniência sedimentar, já que os efeitos do transporte sedimentar e dissolução pós-deposicional sobre a proporção dos tipos de zircão pode ser considerada insignificante.

ESTATÍSTICA DESCRITIVA Para cada amostra foram calculados os índices ZTi, ZRi e as proporções dos tipos morfológicos de zircão. Os valores dos índices ZTi, ZRi e as porcentagens de grãos arredondados de zircão foram categorizados por unidades estratigráficas e fácies sedimentares e resumidos por estatísticas descritivas (média, desvio padrão, quartis, mediana, máximo e mínimo).

\section{RESULTADOS}

Descrição de fácies e petrografia de seções delgadas As fácies do Grupo Guaritas (Fig. 3), amostradas para análises petrográficas de seções delgadas e de minerais pesados, encontram-se descritas na tabela 1 .

As principais características texturais e mineralógicas e a classificação petrográfica, segundo Folk (1968), das amostras estudadas são descritas na tabela 2.

Os arenitos das unidades predominantemente eólicas (formações Pedra Pintada e Pedra da Arara) equivalem a litoarenitos e sublitoarenitos enquanto que os arenitos aluviais (formações Varzinha e Serra do Apertado) são classificados como subarcóseos e sublitoarenitos. O arcabouço é constituido por grãos de quartzo (monocristalino e policristalino, ambos com extinção homogênea ou ondulante), feldspato, às vezes sericitizado, (plagioclásio e feldspato potássico) e fragmentos líticos (xisto, granito, filito, quartzito e arenito). Dentre os feldspatos potássicos, ocorrem grãos bem preservados de microclínio. A composição dos fragmentos líticos das formações Varzinha e Serra do Apertado (unidades fluviais) compreendem todos esses litotipos, enquanto que nas formações Pedra Pintada e Pedra da Arara (unidades eólicas) foram observados apenas fragmentos de xisto e granito. Os grãos de quartzo e feldspato apresentam-se subarredondados, com empacotamento mais 

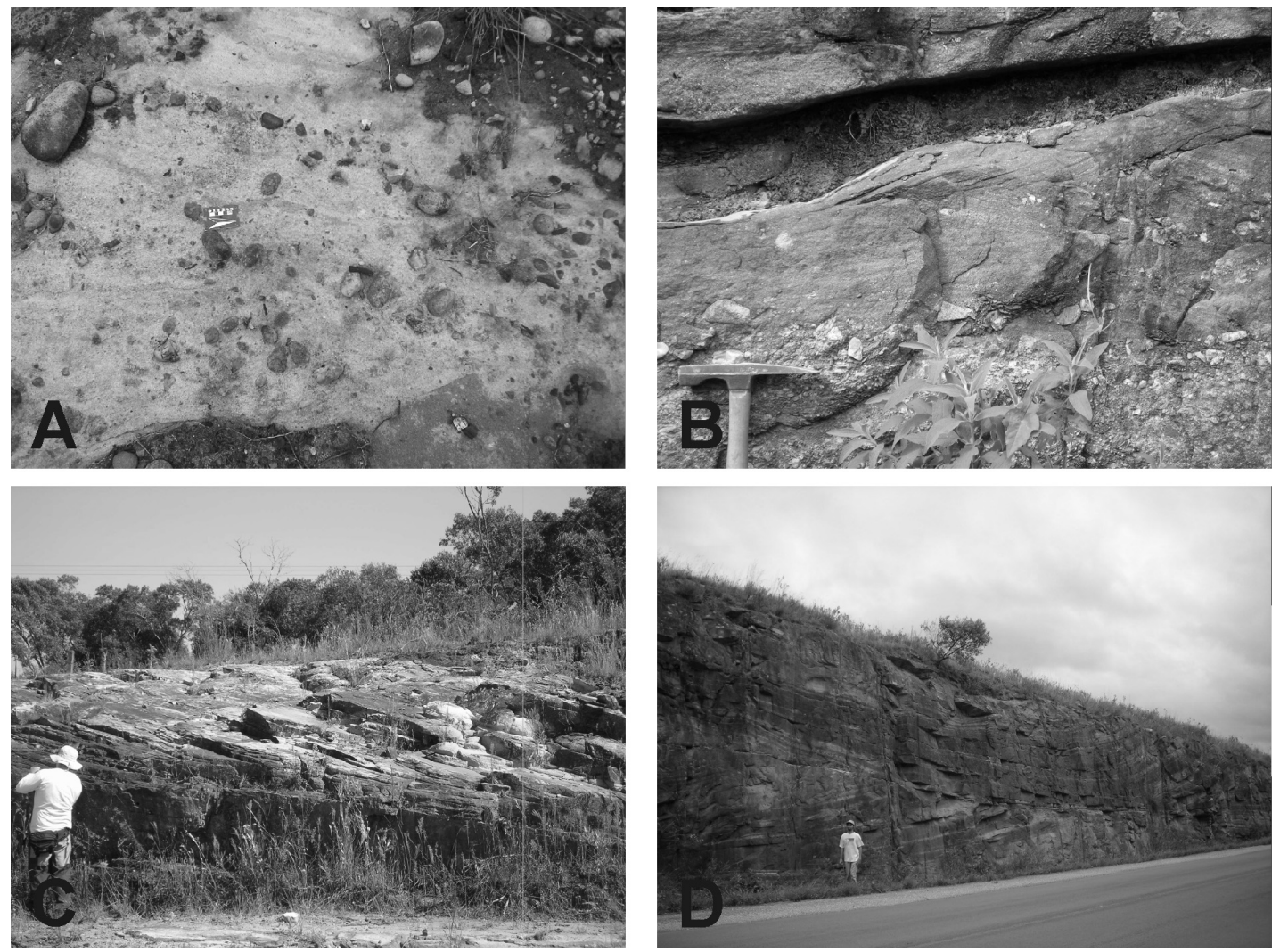

Figura 3 - Fácies sedimentares amostradas para petrografia de seções delgadas e análise de minerais pesados das formações: A. Serra do Apertado (ACc); B. Varzinha (ACc); C. Pedra Pintada (AFC); D. Pedra da Arara $(A F C)$.

Tabela 1 - Fácies sedimentares das formações Varzinha, Pedra Pintada, Pedra da Arara e Serra do Apertado, amostradas para petrografia de seções delgadas e análise de minerais pesados. As letras maiúsculas das siglas das fácies referem-se à características granulométricas e as letras minúsculas às estruturas sedimentares diagnósticas.

\begin{tabular}{|c|c|c|}
\hline Fácies sedimentares & $\begin{array}{l}\text { Unidades } \\
\text { estratigráficas }\end{array}$ & $\begin{array}{l}\text { Sistemas deposicionais } \\
\text { (Almeida, 2005) }\end{array}$ \\
\hline $\begin{array}{l}\text { Arenito fino com estratificação cruzada acanalada em séries decimétricas a } \\
\text { métricas (AFc). A gênese desta fácies é atribuída à migração de dunas barcanas } \\
\text { (facies eólica dunar). }\end{array}$ & $\begin{array}{l}\text { Fm. Pedra Pintada } \\
\text { Fm. Pedra da Arara }\end{array}$ & $\begin{array}{l}\text { Sistema eólico - associação } \\
\text { de fácies de campo de dunas }\end{array}$ \\
\hline $\begin{array}{l}\text { Arenito fino com estratificação plano-paralela em séries métricas (AFpg). } \\
\text { Ocorrem níveis pelíticos gretados ou contínuos. Fácies formada pela acumulação } \\
\text { de areia em planície interdunar susceptível à períodos de inundação } \\
\text { (fácies eólica de planície interdunar). }\end{array}$ & Fm. Pedra Pintada & $\begin{array}{l}\text { Sistema eólico- associação de } \\
\text { fácies de planície interdunar }\end{array}$ \\
\hline $\begin{array}{l}\text { Arenito conglomerático e conglomerado com estratificação cruzada acanalada em } \\
\text { séries decimétricas a métricas (ACc). Fácies formada por migração de barras de } \\
\text { cascalho em sistema fluvial. }\end{array}$ & $\begin{array}{l}\text { Fm. Serra do Apertado } \\
\text { Fm. Varzinha }\end{array}$ & Sistema fluvial entrelaçado \\
\hline $\begin{array}{l}\text { Arenito fino com estratificação plano-paralela e laminação heterolítica (AFph). } \\
\text { Depósitos associados à planície de inundação. }\end{array}$ & Fm. Varzinha & Sistema fluvial entrelaçado \\
\hline $\begin{array}{l}\text { Arenito fino com estratificação plano-paralela em séries decimétricas (AFp). } \\
\text { Deposição de areia em depressão interdunar seca. }\end{array}$ & Fm. Pedra Pintada & $\begin{array}{l}\text { Sistema eólico - associação } \\
\text { de fácies de campo de dunas }\end{array}$ \\
\hline $\begin{array}{l}\text { Arenito com grânulos e seixos e estratificação plano-paralela (ACp). } \\
\text { Fácies de canal fluvial. }\end{array}$ & Fm. Pedra da Arara & Sistema fluvial entrelaçado \\
\hline
\end{tabular}

aberto (formações Varzinha, Pedra Pintada e Pedra da Arara), e subangulosos, com empacotamento mais fe- chado (Formação Serra do Apertado). O grau de seleção (sensu Folk, 1968) pode ser alto (Formação Varzinha), 
médio (formações Pedra Pintada e Pedra da Arara) e baixo (Formação Serra do Apertado). O cimento predominante é carbonático, ocorrendo na forma policristalina e subordinadamente monocristalina. Cimento de óxido de ferro aureolar predomina em relação ao preenchimento parcial de poros. Também ocorre cimento silicoso, com textura fibrorradiada (calcedônia).

Descrição da assembléia de minerais pesados Os minerais pesados identificados foram: zircão, turmalina, rutilo, anatásio, apatita, granada, monazita, sillimanita, cianita, epidoto e fluorita (Figs. 4 e 5). O zircão ocorre em grãos bem arredondados a euédricos, em prismas curtos ou longos. A turmalina ocorre nas variedades de cor verde, marrom e azul. Os grãos de rutilo são bem arredondados e apresentam tons avermelhados. $\mathrm{O}$ anatásio ocorre como grãos euédricos equidimensionais. A apatita apresenta-se em grãos equidimensionais arredondados e prismáticos subédricos. Grãos de zircão, apatita, turmalina, rutilo e anatásio dominam a assembléia de minerais pesados enquanto que grãos de monazita, sillimanita, cianita, granada, epidoto e fluorita

Tabela 2 - Descrição petrográfica e classificação (sensu Folk, 1968) das amostras de arenitos das formações Varzinha, Pedra Pintada, Pedra da Arara e Serra do Apertado.

\begin{tabular}{|c|c|c|c|c|c|c|}
\hline Formação & Fácies & $\begin{array}{l}\text { Granulação } \\
\text { modal }\end{array}$ & $\begin{array}{l}\text { Grau de seleção e } \\
\text { arredodamento }\end{array}$ & $\begin{array}{l}\text { Componentes do } \\
\text { arcabouço }\end{array}$ & $\begin{array}{l}\text { Principais } \\
\text { tipos de } \\
\text { cimentos }\end{array}$ & $\begin{array}{l}\text { Classificação } \\
\text { petrográfica }\end{array}$ \\
\hline Varzinha & $\begin{array}{l}\text { ACc e } \\
\text { AFph }\end{array}$ & $\begin{array}{l}\text { Areia média e } \\
\text { areia muito fina }\end{array}$ & $\begin{array}{l}\text { Alto grau de seleção, } \\
\text { predomínio de grãos } \\
\text { subarredondados e } \\
\text { empacotamento aberto }\end{array}$ & $\begin{array}{l}\text { Feldspato, quartzo } \\
\text { e fragmentos líticos } \\
\text { (quartzito, granito, } \\
\text { xisto e arenito) }\end{array}$ & $\begin{array}{l}\text { Carbonato, } \\
\text { óxido de ferro e } \\
\text { silicoso }\end{array}$ & $\begin{array}{l}\text { Subarcóseo e } \\
\text { sublitoarenito }\end{array}$ \\
\hline Pedra Pintada & $\begin{array}{l}\text { AFc, } \\
\text { AFp e } \\
\text { AFpg }\end{array}$ & $\begin{array}{l}\text { Areia média e } \\
\text { fina, às vezes } \\
\text { muito fina }\end{array}$ & $\begin{array}{l}\text { Grau de seleção médio, } \\
\text { predomínio de grãos } \\
\text { subarredondados e } \\
\text { empacotamento aberto }\end{array}$ & $\begin{array}{l}\text { Feldspato, quartzo } \\
\text { e fragmentos líticos } \\
\text { (xisto e granito) }\end{array}$ & $\begin{array}{l}\text { Carbonato e } \\
\text { óxido de ferro }\end{array}$ & $\begin{array}{l}\text { Litoarenito a } \\
\text { quartzo-arenito }\end{array}$ \\
\hline Pedra da Arara & $\mathrm{AFc}$ & $\begin{array}{l}\text { Areia média, } \\
\text { às vezes fina e } \\
\text { muito fina }\end{array}$ & $\begin{array}{l}\text { Grau de seleção médio, } \\
\text { predomínio de grãos } \\
\text { subarredondados e } \\
\text { empacotamento aberto }\end{array}$ & $\begin{array}{l}\text { Feldspato, quartzo } \\
\text { e fragmentos líticos } \\
\text { (xisto e granito) }\end{array}$ & $\begin{array}{l}\text { Carbonato e } \\
\text { óxido de ferro, } \\
\text { raramente } \\
\text { silicoso }\end{array}$ & $\begin{array}{l}\text { Sublitoarenito, } \\
\text { às vezes } \\
\text { subarcóseo e } \\
\text { litoarenito }\end{array}$ \\
\hline Serra do Apertado & $\mathrm{ACc}$ & Areia média & $\begin{array}{l}\text { Baixo grau de seleção, } \\
\text { predomínio de grãos } \\
\text { subangulosos e } \\
\text { empacotamento fechado }\end{array}$ & $\begin{array}{l}\text { Feldspato, quartzo } \\
\text { e fragmentos líticos } \\
\text { (quartzito, granito, } \\
\text { xisto e arenito) }\end{array}$ & $\begin{array}{l}\text { Carbonato, } \\
\text { óxido de ferro e } \\
\text { silicoso }\end{array}$ & $\begin{array}{l}\text { Subarcóseo e } \\
\text { Sublitoarenito }\end{array}$ \\
\hline
\end{tabular}

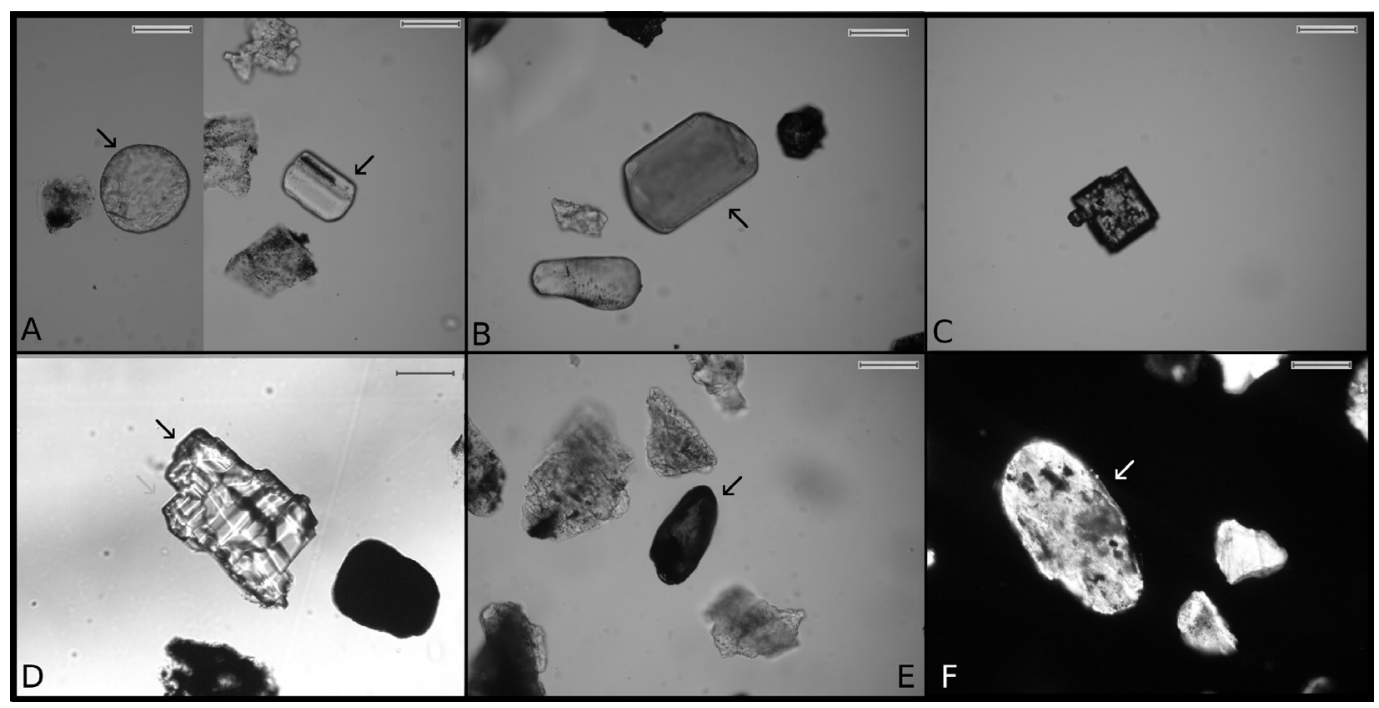

Figura 4 - Minerais pesados identificados em amostras de arenitos do Grupo Guaritas. A. Apatita arredondada e subédrica; B. Turmalina; C. Anatásio; D. Granada; E. Rutilo; F. Sillimanita fibrosa. Imagens a polarizadores paralelos, exceto imagem F. A escala corresponde a $100 \mu \mathrm{m}$. 


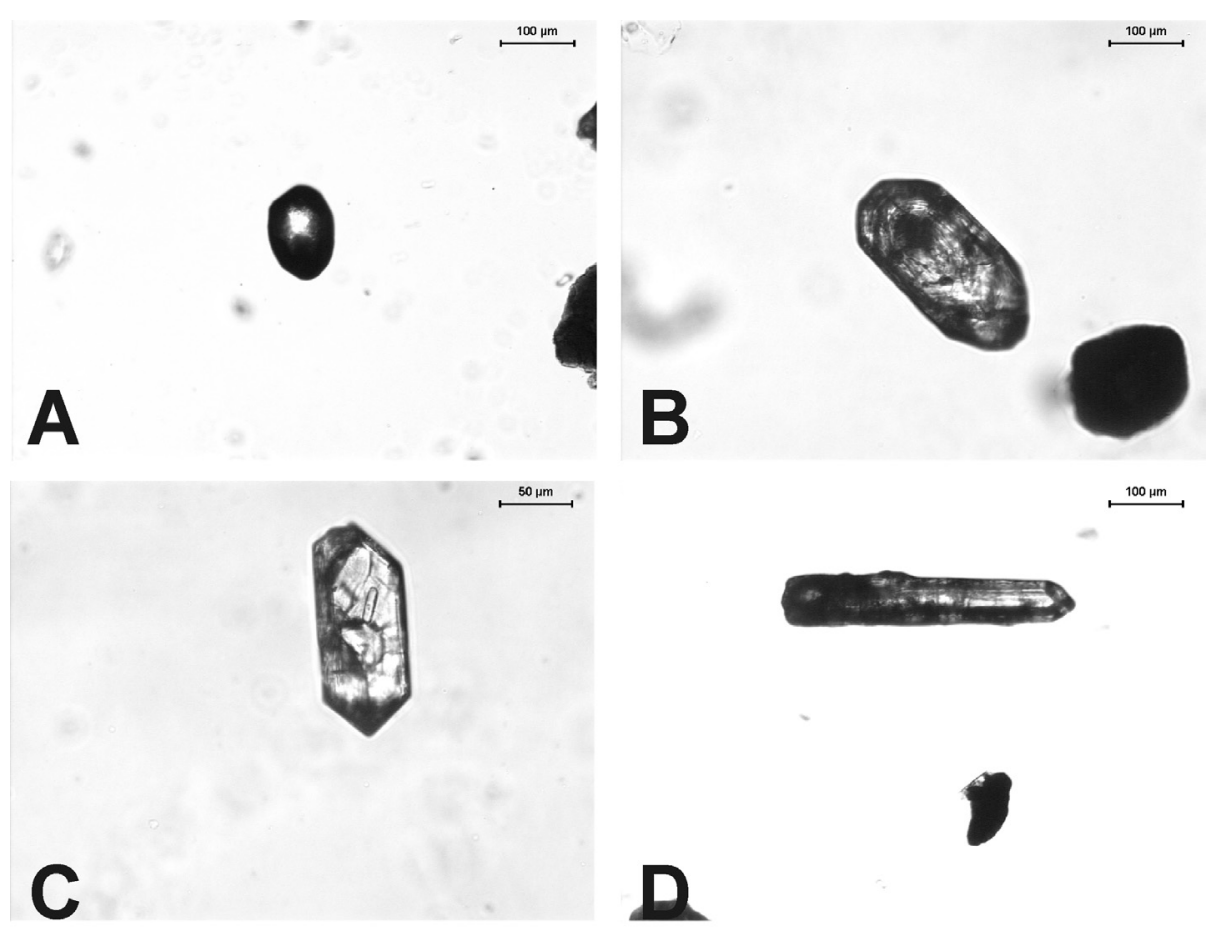

Figura 5 - Variedades morfológicas de zircão: A. Arredondado curto (AC); $B$. subarredondado curto (SC); C. Euédrico curto (EC); D. Euédrico longo (EL).

ocorrem em proporções muito baixas. Destacam-se os elevados teores de apatita ( 0 a $64 \%$ ) e zircão (13 a $82 \%$ ), os quais dominam a assembléia de minerais pesados das unidades estudadas.

Os minerais pesados zircão, turmalina, rutilo, anatásio, apatita, granada e sillimanita foram identificados em todas as unidades (Tab. 3). Não foram observados grãos de monazita na Formação Pedra Pintada. A Formação Varzinha destaca-se pela presença de grãos de cianita, fluorita e epidoto. A tabela 4 apresenta as proporções dos minerais pesados observados nas unidades Varzinha, Pedra Pintada, Pedra da Arara e Serra do Apertado. São apresentadas apenas as proporções dos minerais pesados de amostras isentas de ataque por $\mathrm{HCl} 10 \%$, já que notou-se redução significativa da proporção de apatita nas amostras submetidas ao ata- que ácido. Nestas amostras a Formação Pedra da Arara apresenta indice ZTR maior que os encontrado nas formações Varzinha e Pedra Pintada.

Foram reconhecidas quatro variedades morfológicas de zircão, diferenciadas pelo grau de arredondamento e comprimento do prisma. Foram definidas três categorias de grau de arredondamento: euédrico (cristais com vértices bem definidos), subarredondado (cristais sem vértices, porém com arestas bem definidas) e arredondado (cristais desprovidos de vértices e arestas). As categorias de comprimento do prisma foram definidas pela razão entre os eixos cristalográficos $a$ e $c$ : prisma curto $(c / a<3)$ e prisma longo $(c / a>3)$. Isto permitiu o reconhecimento de quatro tipos morfológicos de grãos de zircão: arredondado curto (AC), subarredondado curto $(\mathrm{SC})$, euédrico curto $(\mathrm{EC})$ e euédrico

Tabela 3 - Minerais pesados transparentes não-micáceos identificados nas unidades estratigráficas estudadas. $(Z I R=$ zircão, $T U R=$ turmalina, $R U T=$ rutilo, $A P A=$ apatita, $A N A=$ Anátasio, GRA = granada, SIL $=$ sillimanita, $M O N=$ monazita, $E P I=$ epidoto, $C I A=$ cianita, $F L U=$ fluorita $)$.

\begin{tabular}{l|c|c|c|c|c|c|c|c|c|c|c}
\hline Unidade estratigráfica & ZIR & TUR & RUT & APA & ANA & GRA & SIL & MON & EPI & CIA & FLU \\
\hline Fm. Varzinha & $\mathrm{X}$ & $\mathrm{X}$ & $\mathrm{X}$ & $\mathrm{X}$ & $\mathrm{X}$ & $\mathrm{X}$ & $\mathrm{X}$ & $\mathrm{X}$ & $\mathrm{X}$ & $\mathrm{X}$ & $\mathrm{X}$ \\
\hline Fm. Pedra Pintada & $\mathrm{X}$ & $\mathrm{X}$ & $\mathrm{X}$ & $\mathrm{X}$ & $\mathrm{X}$ & $\mathrm{X}$ & $\mathrm{X}$ & & & & \\
\hline Fm. Pedra da Arara & $\mathrm{X}$ & $\mathrm{X}$ & $\mathrm{X}$ & $\mathrm{X}$ & $\mathrm{X}$ & $\mathrm{X}$ & $\mathrm{X}$ & $\mathrm{X}$ & & & \\
\hline Fm. Serra do Apertado & $\mathrm{X}$ & $\mathrm{X}$ & $\mathrm{X}$ & $\mathrm{X}$ & $\mathrm{X}$ & $\mathrm{X}$ & $\mathrm{X}$ & $\mathrm{X}$ & & & \\
\hline
\end{tabular}


Tabela 4 - Assembléia de minerais pesados para as amostras não submetidas ao ataque ácido.

\begin{tabular}{c|c|c|c|c|c|c|c|c|c}
\hline Ponto & Unidade & zircão & turmalina & rutilo & ZTR & apatita & anatasio & granada & Outros=1 \\
\hline 4 & Varzinha & 24 & 3 & 1 & 28 & 38 & 4 & 29 & cianita \\
\hline 5 & Varzinha & 31 & 5 & 0 & 36 & 48 & 11 & 5 & 0 \\
\hline 37 & Varzinha & 13 & 7 & 0 & 20 & 54 & 6 & 20 & 0 \\
\hline 10 & Pedra Pintada & 16 & 11 & 0 & 27 & 64 & 6 & 2 & sillimanita \\
\hline 14 & Pedra Pintada & 28 & 3 & 3 & 34 & 63 & 1 & 5 & sillimanita \\
\hline 19 & Pedra da Arara & 43 & 8 & 2 & 53 & 39 & 8 & 0 \\
\hline 22 & Pedra da Arara & 22 & 19 & 5 & 46 & 36 & 8 & 10 & 0 \\
\hline 23 & Pedra da Arara & 17 & 16 & 2 & 35 & 52 & 7 & 5 & sillimanita \\
\hline 42 & Pedra da Arara & 38 & 6 & 1 & 45 & 52 & 2 & 1 & 0 \\
\hline
\end{tabular}

longo (EL) (Fig. 5).

Estatísticas dos índices ZTi, ZRi e das porcentagens dos tipos morfológicos de zircão Foram calculados, para cada amostra, os índices ZTi (zircão/ (turmalina+zircão)) e ZRi (zircão/(rutilo+zircão)) e as proporções relativas dos tipos morfológicos de zircão (AC, SC, EC e EL). O índice ZTR não foi computado, pois foi notada redução significativa do teor em apatita em amostras tratadas com $\mathrm{HCl}$ para eliminação de cimento carbonático. Por esse motivo, optou-se pela utilização de índices mineralógicos independentes da assembléia total de minerais pesados.

Estatísticas descritivas dos índices ZTi e ZRi e das proporções de tipos morfológicos de zircão foram calculadas para as unidades em estudo. Isto permitiu classificar e comparar as unidades estratigráficas do Grupo Guaritas segundo a proveniência sedimentar primária e grau de retrabalhamento dos seus sedimentos.

As formações Varzinha, Pedra Pintada e Pedra da Arara apresentaram valores médios similares dos índices ZTi e ZRi. A Formação Serra do Apertado diferencia-se das demais pelo valor médio mais elevado do índice ZTi. As estatísticas descritivas dos índices ZTi e ZRi para as unidades estudadas são apresentadas na tabela 5 .

Devido à baixa diversidade mineralógica da assembléia de minerais pesados, realizou-se a análise morfológica de grãos de zircão, com o objetivo de identificar assinaturas de proveniência mais específicas para as unidades estudadas. As categorias texturais de grãos de zircão foram representadas por porcentagens derivadas da contagem de no mínimo 17 e máximo de 100 grãos de zircão por amostra. A assembléia de grãos de zircão é dominada por grãos do tipo SC (subarredondado curto), que apresentou porcentagem média entre 76,3 (Formação Pedra da Arara) e 84,3\% (Formação Pedra Pintada). A Formação Serra do Apertado
Tabela 5 - Estatísticas descritivas dos indices ZTi e ZRi obtidas para as unidades estratigráficas do Grupo Guaritas.

\begin{tabular}{|c|c|c|c|}
\hline Estatística & Unidade estratigráfica & $\mathrm{ZTi}$ & $\mathrm{ZRi}$ \\
\hline \multirow{4}{*}{ Média } & Fm. Varzinha & 74,7 & 95,1 \\
\hline & Fm. Pedra Pintada & 75,2 & 92,4 \\
\hline & Fm. Pedra da Arara & 71,1 & 92,6 \\
\hline & Fm. Serra do Apertado & 81,8 & 95,9 \\
\hline \multirow{4}{*}{$\begin{array}{l}\text { Desvio } \\
\text { Padrão }\end{array}$} & Fm. Varzinha & 14,0 & 4,8 \\
\hline & Fm. Pedra Pintada & 13,9 & 5,4 \\
\hline & Fm. Pedra da Arara & 15,3 & 4,5 \\
\hline & Fm. Serra do Apertado & 9,6 & 0,9 \\
\hline \multirow{4}{*}{ Mínimo } & Fm. Varzinha & 47,0 & 84,0 \\
\hline & Fm. Pedra Pintada & 55,7 & 82,6 \\
\hline & Fm. Pedra da Arara & 37,0 & 86,0 \\
\hline & Fm. Serra do Apertado & 69,9 & 95,0 \\
\hline \multirow{4}{*}{ Máximo } & Fm. Varzinha & 94,0 & 99,0 \\
\hline & Fm. Pedra Pintada & 93,0 & 96,0 \\
\hline & Fm. Pedra da Arara & 88,0 & 99,0 \\
\hline & Fm. Serra do Apertado & 91,0 & 97,0 \\
\hline \multirow{4}{*}{$\mathrm{N}$} & Fm. Varzinha & 9 & 9 \\
\hline & Fm. Pedra Pintada & 6 & 6 \\
\hline & Fm. Pedra da Arara & 10 & 10 \\
\hline & Fm. Serra do Apertado & 4 & 4 \\
\hline
\end{tabular}

distingue-se pela maior porcentagem média de grãos euédricos $(\mathrm{EC}+\mathrm{EL}=8,7 \%)$ e menor porcentagem média de grãos arredondados $(\mathrm{AC}=9,1 \%)$. As estatísticas descritivas da quantificação dos tipos morfológicos de zircão são apresentadas na tabela 6 . 
Tabela 6 - Estatísticas descritivas das porcentagens dos tipos morfológicos de zircão reconhecidos nas unidades estratigráficas do Grupo Guaritas. $A C=$ arredondado curto; $S C=$ subédrico/subarredondado curto; $E C=$ enédrico curto; $E L=$ enédrico longo.

\begin{tabular}{|c|c|c|c|c|c|}
\hline Estatística & Unidade estratigráfica & $\mathrm{AC}$ & $\mathrm{SC}$ & $\mathrm{EC}$ & EL \\
\hline \multirow{4}{*}{ Média } & Fm. Varzinha & 13,0 & 83,3 & 2,8 & 0,9 \\
\hline & Fm. Pedra Pintada & 11,6 & 84,3 & 3,5 & 0,7 \\
\hline & Fm. Pedra da Arara & 19,1 & 76,3 & 4,0 & 0,7 \\
\hline & Fm. Serra do Apertado & 9,1 & 82,3 & 7,9 & 0,8 \\
\hline \multirow{4}{*}{$\begin{array}{l}\text { Desvio } \\
\text { Padrão }\end{array}$} & Fm. Varzinha & 8,1 & 7,7 & 1,9 & 1,4 \\
\hline & Fm. Pedra Pintada & 5,0 & 4,3 & 4,2 & 1,1 \\
\hline & Fm. Pedra da Arara & 10,9 & 14,1 & 4,5 & 0,8 \\
\hline & Fm. Serra do Apertado & 4,0 & 6,4 & 1,7 & 1,5 \\
\hline \multirow{4}{*}{ Mínimo } & Fm. Varzinha & 5,6 & 69,0 & 0,0 & 0,0 \\
\hline & Fm. Pedra Pintada & 5,9 & 78,0 & 1,1 & 0,0 \\
\hline & Fm. Pedra da Arara & 7,6 & 42,0 & 0,0 & 0,0 \\
\hline & Fm. Serra do Apertado & 6,7 & 73,0 & 5,6 & 0,0 \\
\hline \multirow{4}{*}{ Máximo } & Fm. Varzinha & 28,7 & 92,1 & 6,6 & 3,4 \\
\hline & Fm. Pedra Pintada & 19,8 & 89,5 & 11,8 & 2,2 \\
\hline & Fm. Pedra da Arara & 46,6 & 88,6 & 12,8 & 2,2 \\
\hline & Fm. Serra do Apertado & 15,0 & 87,6 & 9,3 & 3,0 \\
\hline \multirow{4}{*}{$\begin{array}{l}\mathrm{N} \\
\text { (grãos) }\end{array}$} & Fm. Varzinha & 87 & 577 & 21 & 6 \\
\hline & Fm. Pedra Pintada & 50 & 352 & 8 & 4 \\
\hline & Fm. Pedra da Arara & 169 & 680 & 35 & 6 \\
\hline & Fm. Serra do Apertado & 27 & 221 & 21 & 3 \\
\hline \multirow{4}{*}{$\begin{array}{l}\mathrm{N} \\
\text { (amostras) }\end{array}$} & Fm. Varzinha & 9 & 9 & 9 & 9 \\
\hline & Fm. Pedra Pintada & 6 & 6 & 6 & 6 \\
\hline & Fm. Pedra da Arara & 10 & 10 & 10 & 10 \\
\hline & Fm. Serra do Apertado & 4 & 4 & 4 & 4 \\
\hline
\end{tabular}

DISCUSSÃO O embasamento subjacente da Bacia do Camaquã é formado predominantemente por rochas metamórficas das unidades Dom Feliciano e RioVacacaí e por rochas graníticas neoproterozóicas. Os minerais pesados identificados foram: zircão, apatita, turmalina, anatásio, granada, rutilo, monazita, sillimanita, epídoto, cianita e fluorita. A presença de sillimanita e cianita indicaria rochas metamórficas aluminosas como fonte dos sedimentos das porções média e superior do Grupo Guaritas. No entanto, a baixa proporção destes minerais permite supor que as rochas metamórficas atuaram como fonte subordinada. Isto é compatível com a pequena quantidade de grãos de rutilo, que apesar de ocorrer em rochas ígneas, é mais freqüente em rochas metamórficas (especialmente em rochas de alto grau) (Mange \& Maurer, 1992). Apatita, turmalina, granada, epídoto e monazita ocorrem tanto em rochas ígneas quanto em rochas metamórficas (Deer et al. 1992; Klein,
2002). Fluorapatita (variedade mais comum de apatita) é mineral acessório típico de rochas graníticas enquanto que epídoto é mais freqüente em rochas ígneas básicas e turmalina predomina em rochas ígneas ácidas (Mange \& Maurer, 1992). Zircão é mineral acessório úbiquo em rochas ígneas ácidas. Porém, é freqüente em rochas metamórficas e sedimentares, onde está presente como cristal herdado. A presença de grãos superarredondados de zircão seria indicativa de rocha-fonte sedimentar. A abundância de grãos de zircão (até $82 \%$ ) e apatita (até 64\%) nos sedimentos das porções média e superior do Grupo Guaritas, associada à baixa proporção de minerais tipicamente metamórficos, permite interpretar área-fonte dominada por rochas ígneas graníticas. Os granitos neoproterozóicos, os quais abrangem os granitos Caçapava do Sul (Remus et al. 2000), Lavras do Sul (Nardi \& Lima 2000), Ramada (Naime \& Nardi 1991), São Sepé (Mattos et al. 2004), além do batólito Pelotas (Phillipp \& Machado 2001), têm como minerais acessórios zircão, apatita, turmalina, granada, titanita, anfibólio, epídoto e fluorita. Segundo Morton (1985), anfibólio, epídoto e titanita são minerais instáveis em condições diagenéticas de grande profundidade (fluidos alcalinos), enquanto que granada e apatita são estáveis e turmalina e zircão são ultraestáveis. A cimentação carbonática amplamente distribuída nos arenitos analisados implicaria em fluidos diagenéticos alcalinos. Grãos euédricos de anatásio (até $22 \%$ ) podem ser oriundos da transformação diagenética de grãos de titanita. Assim, a associação mineralógica zircão-apatita-turmalina-granada, que domina os sedimentos analisados, indicaria que os granitos neoproterozóicos foram as principais rochas-fonte dos sedimentos do Grupo Guaritas. Isto poderia indicar maior área de exposição e/ou maior declividade das áreas com rochas ígneas ácidas aflorantes.

As rochas do Grupo Guaritas correspondem a subarcóseos, sublitoarenitos e litoarenitos (sensu Dott 1964). Esses resultados são compatíveis com os apresentados por De Ros et al. (1994), que classificam estas rochas como arcóseos líticos e litoarenitos arcoseanos (sensu Folk 1968). Análises modais realizadas por De Ros et al. (1994) indicaram que os fragmentos líticos dos arenitos do Grupo Guaritas abrangem em média 5,5\% de rochas vulcânicas, $4,3 \%$ de rochas metamórficas e $0,1 \%$ de rochas sedimentares. Com base na variação espacial destes resultados, estes autores propuseram qua a principal área-fonte dos sedimentos do Grupo Guaritas estaria localizada a oeste da Bacia do Camaquã. No entanto, os fragmentos líticos das rochas de granulação grossa, tais como as rochas plutônicas, são sub-representados nos arenitos. A grande quantidade de feldspatos é concordante com a abundância de apatita na assembléia de minerais pesados, pois ambos minerais são instáveis em condições de intemperismo úmido, sugerindo ambiente árido e/ou elevadas taxas de deposição para os sedimentos do Grupo Guaritas.

Os valores do índice ZTR indicam maior retrabalhamento da Formação Pedra da Arara (35-53) em relação às formações Varzinha (20-36) e Pedra Pintada (27-34). Os valores similares dos índices ZTi $(0,71$ - 
0,82) e ZRi $(0,92-0,96)$, nas unidades estudadas do Grupo Guaritas, apontam, respectivamente, sedimentos de grau de retrabalhamento semelhante e manutenção da configuração das áreas-fonte e do sistema de captação dos sedimentos. A Formação Serra do Apertado distingue-se das demais unidades por possuir valores mais elevados do índice ZTi e das porcentagens de zircões euédricos $(E C+E L)$. Valores mais elevados do índice ZTi indicam maior concentração de grãos de zircão em relação aos grãos de turmalina, que pode ser interpretado como maior grau de retrabalhamento dos sedimentos da Formação Serra do Apertado. Porém, o aumento das porcentagens de grãos euédricos de zircão seria indicativo de mudanças composicionais do aporte sedimentar, com incremento da contribuição de sedimentos derivados diretamente de rochas ígneas em detrimento aos derivados de rochas sedimentares ou metassedimentares. As diferenças de proveniência entre a Formação Serra do Apertado e as unidades subjacentes são coerentes com a discordância que a separa das unidades subjacentes (Ribeiro et al. 1966, Fragoso-Cesar 1991, Paim et al. 1995, 2000, Almeida 2005, Almeida et al. 2008)

CONCLUSÕES (1) As análises de minerais pesados sugerem que os sedimentos do Grupo Guaritas são derivados principalmente de rochas ígneas ácidas (granitos neoproterozóicos) e subordinadamente de rochas meta- mórficas e sedimentares.

(2) A abundância de apatita indica deposição em ambiente árido e/ou soterramento rápido, seguida de intensa dissolução diagenética dos minerais instáveis sob condições alcalinas.

(3) A similaridade do índice ZRi aponta manutenção da configuração litológica da área-fonte durante a sedimentação das unidades estudadas.

(4) Os valores semelhantes do índice ZTi registram pequena variação no grau de retrabalhamento dos sedimentos das unidades do Grupo Guaritas.

(5) A Formação Serra do Apertado é diferenciada das demais unidades por possuir índice ZTi mais elevado e maior proporção de grãos euédricos de zircão. Estas características permitem interpretar mudanças na dinâmica do sistema deposicional, representada pelo incremento do retrabalhamento sedimentar, e na configuração da área-fonte, representada pelo aumento da proporção de sedimentos derivados de rochas ígneas ácidas.

Agradecimentos Este estudo foi financiado pela Fundação de Amparo à Pesquisa do Estado de São Paulo (projeto auxílio à pesquisa processo: 05/50655-0). Os autores agradecem os geólogos Felipe Torres Figueiredo, André Marconato, Rogério Brandi de Sousa e Maurício Guerreiro M. dos Santos pelo auxílio nos trabalhos de campo e nas coletas de amostras.

\section{Referências}

Almeida R.P. de 2005. Tectônica e Sedimentação do Ediacariano ao Ordoviciano: Exemplos do Supergrupo Camaquã (RS) e do Grupo Caacupé (Paraguai Oriental). Tese de Doutoramento, Instituto de Geociências, Universidade de São Paulo, 183p.

Almeida R.P., Janikian L., Fragoso-Cesar A.R.S., Marconato A. (Submetido). Evolution of a rift basin dominated by subaerial deposits: the Guaritas Rift, Early Cambrian, Southern Brazil. Sedimentary Research.

Becker R. \& Fernandes L.A.D. 1982. Caracterização faciológica de uma sequência vulcano-sedimentar eo-paleozóica na Folha Passo do Tigre (RS). Acta Geologica Leopoldensia, 6(13):287-322.

Deer W.A., Howie R.A., Zussman J. 1992. An introduction to the rock-forming minerals. Essex, Longman Scietific \& Technical, 696p.

De Ros L.F., Morad S., Paim P.S.G. 1994. The role of detrital composition and climate on the diagenetic evolution of continental molasses: evidence from the Cambro-Ordovician Guaritas sequence, southern Brazil. Sedimentary Geology, 92(3-4):197-228.

Dott R.H. 1964. Wacke, Graywacke and Matrix - What Approach to Immature Sandstone Classification? Journal of Sedimentary Research, 34(3):625-632.

Faccini U.F., Paim P.S.G., Fragoso-Cesar A.R.S. 1987. Análise faciológica das molassas brasilianas na região das Minas do Camaquã, Eo-paleozóico do RS. In: SBG, Simpósio Sul-Brasileiro de Geologia, 3, Curitiba, Atas,
1:75-91.

Folk R.L. 1968. Petrology of sedimentary rocks. Austin, Hemphill Publ. Co., 170p.

Fragoso-Cesar A.R.S. 1980. O Cráton Rio de La Plata e o Cinturão Dom Feliciano no Escudo Uruguaio-Sul-Riograndense. In: SBG, Congresso Brasileiro de Geologia, 31, Camboriú, Anais, 5:2879-2892.

Fragoso-Cesar A.R.S. 1991. Tectônica de Placas no Ciclo Brasiliano: as Orogenias dos Cinturões Dom Feliciano e Ribeira no Rio Grande do Sul. Tese de Doutoramento, IGc-USP, São Paulo, 366p.

Fragoso-Cesar A.R.S., Lavina E.L., Paim P.S.G., Faccini U.F. 1984. A Antefossa Molássica do Cinturão Dom Feliciano no Escudo do Rio Grande do Sul. In: SBG, Congresso Brasileiro de Geologia, 33, Rio de Janeiro, Anais, 7:3272-3283

Fragoso-Cesar A.R.S., Faccini U.F., Paim P.S.G., Lavina E.L., Altamirano J.A.F. 1985. Revisão na estratigrafia das molassas do Ciclo Brasiliano no Rio Grande do Sul. In: SBG, Simpósio Sul-Brasileiro de Geologia, 2, Florianópolis, Anais, p. 477-491.

Fragoso-Cesar A.R.S., Silva Filho W.F., Fambrini G.L., Machado R., Riccomini C., Almeida R.P., Pelosi A.P.M.R., Janikian L. 1999. Significado tectônico do magmatismo Rodeio Velho no rift Guaritas (Eopaleozóico do Rio Grande do Sul, Brasil). In: Simpósio sobre Vulcanismo e Ambientes Associados, 1, Boletim de resumos, p.16.

Galehouse J.S. 1971. Point-counting. In: Carver R.E. (ed.) 
Procedures in Sedimentary Petrology. New York, WileyInterscience, p. 385-407.

Hubert J.F. 1962. A zircon-tourmaline-rutile maturity index and the independence of the composition of heavy mineral assemblages with the gross composition and texture of sandstones. J. Sediment. Petrol., 32(3):440-450.

Hunter R.E. 1977. Basic types of stratification in small eolian dunes. Sedimentology 24:361-387.

Hunter R.E. 1981. Stratification styles in eolian sandstones: some Pennsylvanian to Jurassic exemples from western interior U.S.A. In: Ethridge F.G. \& Flores R.M. (eds.) Recent and Ancient Nonmarine Depositional Environments: Models for Exploration. SEMP Special Publication, 31:315-329.

Klein C. 2002 Mineral Science. New York, John Wiley \& Sons, 646p.

Lavina E.L., Faccini U.F., Paim P.S.G., Fragoso-Cesar A.R.S. 1985. Ambientes de sedimentação da Bacia do Camaquã, Eo-paleozóico do Rio Grande do Sul. Acta Geologica Leopoldensia, 21(9):185-227.

Mange M.A. \& Maurer H.F.W. 1992. Heavy Minerals in Colours. London, Chapman \& Hall, 147p.

Mattos I.C., Phillipp R.P., Mexias A.S., Gomes M.E.B. 2004. Metamorfismo de contato no Complexo Bossoroca, porção SW do Complexo Granítico São Sepé, RS. Revista Brasileira de Geociências, 34(1):1-10.

Morton A.C. 1985. Heavy minerals in provenance studies. In: Zuffa G.G. (ed.) Provenance of Arenites. Reidel, Dordrecht, p. 249-277.

Morton A.C. \& Hallsworth C.R. 1994. Identifying provenance-specific features of detrital heavy mineral assemblages in sandstones. Sedimentary Geology, 90:241-256.

Morton A.C. \& Hallsworth C.R. 1999. Processes controlling the composition of heavy mineral assemblages in sandstones. Sedimentary Geology, 124:3-29.

Naime R.H. \& Nardi L.V.S. 1991 O granito da Ramada, porção oeste do escudo sul-rio-grandense: geologia, petrologia e geoquímica. Revista Brasileira de Geociências, 21(3):266-274.

Nardi L.V.S. \& Lima E.F. 2000. Hybridisation of mafic microgranular enclaves in the Lavras Granite Complex, southern Brazil. Journal of South American Earth Sciences, 13:67-78.

Paim P.S.G. 1994. Depositional Systems and Paleogeographical Evolution of the Camaquã and Santa Bárbara Basins, Brazil. Phil. Doctor Thesis, Oxford, v.I, 277p.

Paim P.S.G. 1996. O sistema desértico úmido Pedra Pintada (cambro-ordoviciano do RS). In: SBG, Congresso Brasileiro de Geologia, 39, Salvador, Boletim de Resumos Expandidos, 2:207-209.

Paim P.S.G. \& Scherer C.M.S. 2003. Arquitetura Estratigráfica de sucessões flúvio-eólicas: o exemplo do Alogrupo Guaritas na região da Pedra Pintada, Rio Grande do Sul, Brasil. In: Paim P.S.G., Faccini U.F., Netto R.G. (eds.) Geometria, arquitetura e heterogeneidades de corpos sedimentares - Estudos de casos. Unisinos, p. 38-58.

Paim P.S.G., Lopes R.C., Chemale Jr. F. 1995. Aloestratigrafia, sistemas deposicionais e evolução paleogeográfica da Bacia do Camaquã -Vendiano Superior/ Ordoviciano Inferior do RS. In: SBG/Núcleo RS, Simpósio Sul-Brasileiro de Geologia, 6 / Encontro Geologia do Cone Sul, 1, Porto Alegre, Boletim de Resumos Expandidos, p. 39-50.

Paim P.S.G., Chemale Jr. F., Lopes R.C. 2000. A Bacia Camaquã. In: Holtz M. \& de Ross L.F. (eds.) Geologia do Rio Grande do Sul. Universidade Federal do Rio Grande do Sul, p.232-274.

Parfernoff A., Pomerol C., Tourenq J. 1970. Les Minéraux en Grains: Methods d'etude et determination. Paris, Masson, 571p.

Philipp R.P. \& Machado R. 2001. Suítes graníticas do Batólito de Pelotas no Rio Grande do Sul: petrografia, tectônica e aspectos petrogenéticos. Revista Brasileira de Geociências, 31(3):257-266.

Remus M.V.D., Hartmann L.A., Mcnaughton N.J., Groves D.I., Fletcher I.R. 2000. The link between hydrothermal epigenetic copper mineralization and the Caçapava Granite of the Brasiliano Cycle in southern Brazil. Journal of South American Earth Sciences, 13:191-216.

Ribeiro M., Bocchi P.R., Figueiredo Filho P.M., Tessari R.I. 1966. Geologia da quadrícula de Caçapava do Sul, Rio Grande do Sul. Rio de Janeiro, DNPM/DFPM, Boletim 127, 232p.

Robertson J.F. 1966. Revision of Stratigraphy and nomenclature of rock units in Caçapava-Lavras Region. Notas e Estudos, IG-UFRGS, 1(2):41-54.

Van Andel TJ.H. 1950. Provenance, transport and deposition of Rhine sediments. H. Veeman en Zonen, Wageningen, $129 \mathrm{p}$.

Manuscrito ID 11809

Submetido em 18 de maio de 2008 Aceito em 20 de setembro de 2008 Sistema eletrônico de submissão 